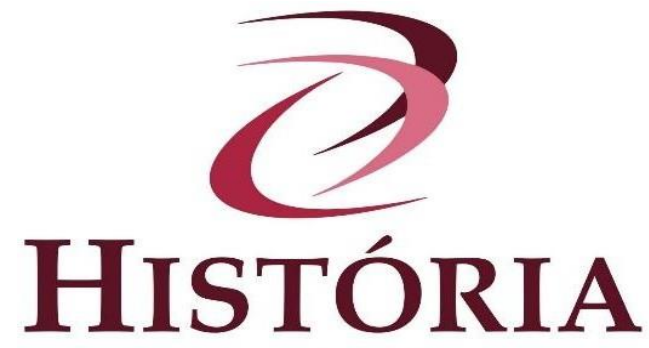

\title{
Clodoaldo Bueno e a História da Política Externa Brasileira: pioneirismo e itinerário intelectual
}

\author{
Daniel Rei Coronato ${ }^{\mathrm{i}}$ \\ Fernando Comiran ${ }^{\text {ii }}$
}

\section{Apresentação}

O campo da Histórica da Política Externa Brasileira se confunde com a trajetória de Clodoaldo Bueno. Não é exagero afirmar a impossibilidade de se estudar a história das relações internacionais do Brasil sem, em algum momento, dialogar com a sua produção bibliográfica e intelectual.

Graduado em História pela Universidade do Estado de São Paulo - UNESP/Marília (1966), mestre (1974) e doutor (1977) em História Econômica pela Universidade de São Paulo (USP), é professor livre-docente (1984) pela Unesp/Marília, onde foi professor titular em uma trajetória de permanente interesse na inserção internacional do Brasil. Atuou como professor visitante na Universidade de Brasília (UnB) e no Instituto de Estudos Avançados da Universidade de São Paulo. Integrou o corpo docente fundador do Programa de PósGraduação em História da Unesp/Assis, onde também lecionou no curso de graduação até 2013, e integrou, também, o grupo de docentes fundador do Programa de Pós-Graduação "San Tiago Dantas" (UNESP/UNICAMP/PUC-SP). Foi bolsista do Conselho Nacional de Desenvolvimento Científico e Tecnológico (CNPq), nível I-A.

Da sua densa produção bibliográfica, merecem destaque os livros A República e sua política exterior, 1889-1902 (1995) e Política externa da Primeira República (2003), e, em coautoria com Amado Luiz Cervo, História da política exterior do Brasil (1992), que já está na $5^{\mathrm{a}}$ edição pela Editora da UnB. Esse último se tornou referência na área de estudos da política externa brasileira e na formação da maior parte dos historiadores e internacionalistas dedicados ao tema, considerada a principal obra-síntese da história da política externa brasileira e, provavelmente, um dos livros mais acessados nos cursos de graduação e pós-graduação da área. Publicou textos em Paris, Londres, Milão, Buenos 
Aires, Quito, Tóquio e Assunção.

Além de sua produção historiográfica, orientou estudantes de pós-graduação, em nível de doutorado e mestrado, influenciando diretamente na formação de pesquisadores dos temas internacionais do Brasil. Em sua vasta obra é evidente o rigor metodológico no estudo de seus temas de pesquisa e no meticuloso uso e tratamento das fontes primárias. Sua obra acadêmica, em sua maioria produzida antes do encurtamento das distâncias que as tecnologias da informação hoje nos oferecem, pode ser caracterizada como multiarquivística, pois suas pesquisas foram fruto de um trânsito em diferentes arquivos e centros de documentação.

Nesta entrevista, procuramos ouvir, além de aspectos de sua trajetória pessoal, seu itinerário intelectual, dando atenção para as principais influências teóricas e metodológicas na sua formação e, especialmente, na composição de sua obra. Realizada dentro do contexto da pandemia do novo coronavírus, a entrevista foi realizada através de plataforma virtual em 16 de dezembro de 2020.

\section{Entrevista}

PERGUNTA: O ambiente educacional e de pesquisa se alterou vertiginosamente nas últimas décadas para os interessados em assuntos internacionais. Como foi a sua formação na graduação em História pela Universidade do Estado de São Paulo (UNESP) e quais as suas principais influências ao longo desse período?

Clodoaldo Bueno: Após concluir o ensino médio, recusei boas propostas de emprego, para início imediato, no meu ambiente cartorário, onde comecei a trabalhar quando tinha catorze anos de idade, a fim de me submeter ao exame vestibular para o curso superior de História na Faculdade de Filosofia, Ciências e Letras (FFCL) de Marília, então instituto isolado do ensino superior do Estado de São Paulo. O vestibular organizado e aplicado pelos seus próprios professores consistia em duas semanas de provas escritas e orais nas disciplinas de português, uma língua estrangeira (francês ou inglês), história geral, da América, do Brasil e geografia geral e do Brasil. Não existia no País vestibular classificatório. Mesmo com sobra de vagas, era preciso que o candidato fosse aprovado em todas as provas e alcançasse uma determinada média geral de todas as disciplinas.

Aprovado, matriculei-me no curso oferecido por uma faculdade, cuja existência só tive conhecimento dois meses antes. Sem o saber, acabara de entrar em um dos melhores cursos de história do País. No Estado de São Paulo, era o segundo curso público de História instalado. Pertenço à quinta turma da FFCL, incorporada posteriormente à UNESP quando de sua criação em 1976. 
O corpo docente da FFCL era de excelente qualidade acadêmica. Fui aluno da professora Olga Pantaleão (História Moderna e Contemporânea), que fora assistente de Jean Gagé na USP e doutorara-se na Universidade de Londres; Maria da Conceição Vicente de Carvalho (Geografia Humana), creio que fora uma das (ou a primeira) doutora em Geografia no Brasil, discípula, em Paris, de Pierre Monbeig, que me disse aqui em Marília, que ela era sua "filha intelectual e você, portanto, meu neto"; José Roberto do Amaral Lapa (História do Brasil), conceituado historiador campineiro, teve Sérgio Buarque de Holanda como seu orientador, e encerrou sua brilhante carreira na Unicamp depois de ter passado 14 anos em Marília; Carl Valeer Frans Laga (História Antiga e Medieval), belga, poliglota, um grande humanista; Eddy Odiel Gerard Stols (História Ibérica e História da América), também belga, que juntamente com seu conterrâneo ministravam, também, História da Arte Antiga, Medieval e Contemporânea; Maria Clara Rezende Teixeira Constantino, filósofa portuguesa e Maria Regina da Cunha Rodrigues, historiadora entusiasta, formada na USP, ministraram, respectivamente, Teoria da História e Introdução aos Estudos Históricos; e Osvaldo Elias Xidieh (Sociologia), da mesma turma, creio, de Florestan Fernandes. Por um semestre fiz um curso de história dos Estados Unidos, ministrado em Marília por um norte-americano convidado, Jerome Fischmann. Em virtude dos contatos e do prestígio dos nossos professores assistimos a belos eventos, como palestras, mesas redondas, Semanas de História. O curso de Marília adquiriu bom conceito interno e, até, fora do País. O primeiro simpósio nacional dos professores universitários foi ideia dos professores de Marília, que organizaram e acolheram em 1961 o I Simpósio Nacional, que ao final das sessões criou a Associação Nacional dos Professores Universitários de História (ANPUH). Outro ponto de destaque da FFCL de Marília, era sua riquíssima biblioteca. Sem ela não seria possível a existência de um curso de bom nível. À exceção de História do Brasil, durante a graduação, tínhamos que consultar textos em francês, inglês e espanhol, pois eram poucas as traduções de livros acadêmicos.

Outra característica do ambiente acadêmico proporcionado pelo curso de História, era a ausência de politização. Os anos da minha graduação (1963-66) foram de efervescência política nacional. Havia um Centro Acadêmico com engajamento político e uns poucos docentes de outros cursos, também engajados. No curso de História os professores não falavam em política nem os alunos levantavam assuntos sobre a política nacional em sala de aula ou fora dela. Não sabíamos sequer a tendência política dos nossos docentes. As aulas começavam e terminavam no horário estabelecido, marcavam-se as faltas dos ausentes, havia rigor nas notas de aproveitamento. Poucos passavam para a série seguinte com média suficiente para serem dispensados de exames finais.

O objetivo do curso era a formação de docentes para o ensino médio, mas também, 
a formação de pesquisadores, esta, aliás, era a ênfase do curso. Aprendiam-se técnicas de pesquisa ao longo da graduação nos trabalhos exigidos pelas diferentes disciplinas. Desde sua inauguração, Marília exigia, para o aluno se graduar, defesa pública de uma "tese" de licenciatura, orientada por um de seus docentes, perante banca examinadora de três membros, um deles seu orientador que a presidia. A "tese" era um excelente aprendizado. A redação teria que ser original. $O$ plágio, mesmo em parte, importava em reprovação. $O$ tema era definido conjuntamente entre aluno e orientador, o que geralmente fazia-se ao final do terceiro ano a fim de se aproveitar o recesso de janeiro e fevereiro para pesquisar. A feitura dessa dissertação de final de curso despertou em mim o gosto pelo estudo das relações internacionais. Considerando-se meu pouco conhecimento do universo universitário, a decisão de estudar na FFCL de Marília foi, para mim, um lance de sorte. Feliz fiquei ao me tornar no ano seguinte à minha graduação, professor assistente voluntário do Prof. Stols por um ano e meio antes de ser contratado.

PERGUNTA: Como o senhor começou a estudar/se preocupar em assuntos de Relações Internacionais, mais especificamente na área da Política Externa Brasileira?

Clodoaldo Bueno: Ao concluir meu terceiro ano de graduação dei início à minha dissertação de final de curso. O prof. Stols, então regente da disciplina de História da América, aceitou me orientar, e de nossos contatos resultou a decisão de pesquisar sobre os reflexos diplomáticos da Revolução Mexicana (1910-1917). Da leitura da bibliografia, do texto e dos documentos publicados por Isidro Fabela, Secretário de Relaciones de Carranza, acabei fazendo um trabalho sobre as relações Estados Unidos-México durante a citada revolução. Daí, interessei-me pelo panamericanismo e candidatei-me ao curso de pósgraduação da USP, já sob o então chamado regime novo (sou da primeira turma por este sistema, que é o modelo vigente), apresentando como projeto de mestrado um estudo sobre a III Conferência Internacional Americana realizada no Rio de Janeiro em 1906. Foi nessa oportunidade que tomei contato com parte da documentação do barão do Rio Branco, personagem conhecido, sobretudo pelas suas vitórias nas questões de fronteira em que defendera o Brasil, e senti que faltava um texto que analisasse o conjunto de sua obra no Itamaraty (1902-1912). Assim nasceu minha ideia de fazer uma síntese abrangente com ênfase nas correntes do comércio internacional brasileiro a fim de fundamentar o peso das relações bilaterais Brasil-Estados Unidos. Disso resultou meu doutorado pela USP. 
PERGUNTA: Dentre diversos temas abordados ao longo da sua trajetória, o período da denominada República Velha, incluindo aí o ministério do Barão do Rio Branco, foram os mais importantes. Como se deu o interesse por esse período?

Clodoaldo Bueno: Foi uma sequência natural de meus estudos. O projeto seguinte foi sobre a política externa brasileira no período imediatamente anterior ao de Rio Branco, isto é, do advento da República ao início de sua gestão no Itamaraty. Cheguei a planejar um terceiro volume para cobrir o período 1918-1930 para fechar toda a Primeira República. Enquanto pensava se o fazia ou não, o diplomata e historiador Eugênio Vargas Garcia, me apresentou um belo projeto sobre a política externa brasileira da década de 1920, que ele começara a desenvolver, do qual resultou um excelente e bem cuidado livro. Com isso, a Primeira República ficou bem coberta. Surgiram, também, os trabalhos do Paulo Roberto de Almeida, e de um orientando meu, Adelino Martins, que fez uma bela dissertação de mestrado, na verdade, equivalente a um doutorado, sobre a inserção da economia brasileira na economia mundial na década de 1920, trabalho que já mereceria estar publicado. No momento estou preparando uma segunda edição, revista e ampliada, do livro A República e sua política exterior, há tempo esgotado. Está sendo mais trabalhoso do que imaginei a princípio. Está se tornando quase que um novo livro.

PERGUNTA: O senhor experimentou na sua trajetória um período na Bélgica. Como foi essa experiência?

Clodoaldo Bueno: Fui até lá em busca de fontes. Supervisionado pelo meu antigo mestre em Marília Eddy Stols da Universidade de Lovaina (agora seu professor emérito) encontrei com mais facilidade os caminhos para a consulta de arquivos e bibliotecas. Encontrei muito material na Biblioteca Nacional Leopoldo I. Empregando bem o tempo deu para ir à França consultar o arquivo de Nantes (a França, por razões de segurança descentralizou sua documentação nacional) e o Arquivo dos Negócios Estrangeiros em Paris (Quai d'Orsay). Acabei gastando boa parte do meu tempo neste arquivo, de onde trouxe informações que foram incorporadas ao texto então em preparo.

PERGUNTA: Como o senhor pensa os campos das Relações Internacionais e da História, em especial atualmente?

Clodoaldo Bueno: A realidade objeto de estudo do analista das Relações Internacionais e a do historiador é a mesma, mas as abordagens são distintas. A história ocupa-se do singular, 
do concreto, do irreversível, submetido à força do tempo. A teoria preocupa-se com o presente e busca o comum em situações diversas; estabelece generalizações e tipificações. Os limites estritos da história comportam, basicamente, duas grandes vertentes: as inspiradas em maior ou menor grau no marxismo, dão ênfase ao imperialismo e, ao reduzir as relações internacionais aos seus esquematismos teóricos, empobrecem as análises, e, ao fazer a síntese, acabam refazendo um estudo sobre o capitalismo. Krippendorff é um exemplo acabado. A vertente que me inspira é a que tem como maiores expoentes Renouvin e Duroselle que consideram os eventos na sua especificidade, e acolhendo as "durações" na História nos termos em que Braudel qualificou. Há fatos de curta, média e longa duração de acordo como se projetam no tempo, influenciados por forças que Renouvin designou como "profundas": fatores geográficos, condições climáticas, forças econômicas, questões financeiras, movimentos de mentalidades como o sentimento nacional, nacionalismo, pacifismo. Renouvin e Duroselle valorizam a ação do homem de Estado e sua relação recíproca com as forças profundas. O homem de Estado não é um mero funcionário de situações adstringente predeterminadas, conforme afirma o citado teórico alemão. Para os dois teóricos franceses, não há primazia de determinado fator na "explicação" histórica. Por isso, o pesquisador não deve partir de ideias preconcebidas e analisar cada fator individualmente, aceitando que todos fazem parte de uma totalidade e agem em concomitância. A Ciência Política oferece um leque maior de opções metodológicas se comparada à História; desde os conceitos marxistas aos de inspiração anglo-saxônia existem variações que ensejam mais de uma possibilidade de apreensão do real. O politólogo busca na história, vale dizer, na concretude dos fatos, os fundamentos dos seus modelos explicativos. Até aí tudo bem. O que não é aceitável, é alterar a realidade em favor de posições concebidas a priori. Pecado que, não raro, também acomete o historiador ao desprezar uma fonte que contraria sua "explicação" apriorística. De qualquer forma, história e teoria se entrelaçam nas relações internacionais. Completam-se. Permitam-me ler uma frase do historiador britânico Seeley, retirada de Duroselle (Todo império perecerá): "A história sem a ciência política não dá nenhum fruto; a ciência política sem a história não tem nenhuma raiz".

PERGUNTA: O senhor se formou em um momento que a escola dos Annales e a Nova História tinham grande influência sobre os historiadores brasileiros. Ainda assim, percebemos que sua inclinação foi para outra direção, se aproximando muito daquilo que denominamos de Escola Francesa. O senhor concorda com isso?

Clodoaldo Bueno: Na minha graduação a bibliografia básica utilizada era francesa. No 
referente à teoria e método nossos grandes autores eram Marc Bloch, Lucien Febvre (fundadores da Escola dos Annales) e seguidores imediatos, sobretudo Fernand Braudel. Por isso mesmo, não perco a noção de totalidade, e vejo a História como disciplina de síntese, a regente de uma orquestra, conforme afirmavam os fundadores da Escola, pois ela incorpora o saber proveniente de outras disciplinas, que trabalham com partes do total, como a Economia e as Ciências Sociais. Esse posicionamento exige mais do pesquisador que se vê obrigado a trabalhar com fontes de origem e natureza diversas; não se restringe ao documento escrito, os fatos com os quais trabalha não são apenas o "fato de curta duração", o acontecimento que se encerra nos limites de seu próprio tempo. O historiador deve procurar os "fatos de média e de longa duração", que se processam em níveis abaixo da realidade, não visíveis a olho nu. A meu ver o "fato curto" é um "veículo" que nos leva a perceber (ou suspeitar) que se processam transformações duradouras, em outros níveis, na estrutura da sociedade. Outra consequência dessa maneira de ver a História é a necessidade de conhecer outras disciplinas.

PERGUNTA: Questiona-se: Relações Internacionais é uma disciplina autônoma ou é apenas um conjunto disciplinar. O que o senhor pensa sobre essa questão?

Clodoaldo Bueno: Essa discussão, não diria irrelevante, mas se põe, também, em outras áreas do saber. Para nós é mais interessante chegarmos a um acordo no referente a História das Relações Internacionais e a Teoria das Relações Internacionais. Esta é objeto do cientista político. Ocupa-se dos fenômenos internacionais em geral, enquanto a História das Relações Internacionais oferece uma visão parcial daqueles fenômenos. Para Manuel Medina (politólogo espanhol), seria uma das disciplinas “auxiliar”, embora indispensável para o estudo das relações internacionais. Já Cárdenas Elorduy (mexicano) entende que a história seria um "instrumento" ou "enfoque no estudo da realidade internacional". À teoria estaria reservada a estrutura e evolução do conjunto da sociedade internacional, caracterizada pela integração de unidades políticas independentes e ausência de poder central. Para mim, é até ocioso dizer, que a realidade objeto de estudo de ambas as disciplinas é a mesma, mas existe separação conceitual entre elas. A história estuda o concreto irreversível, submetido à força do tempo, conforme afirmado. A teoria preocupase com o presente e busca o comum em situações diversas, estabelece generalizações, tipificações, e pode ter um caráter pragmático. O historiador, não raro, tem uma teoria que subjaz ou aparece na narrativa que elabora. O teórico adota o caminho inverso: procura inteirar-se da narrativa histórica para demonstrar/validar sua teoria. Embora os teóricos reconheçam que a história das relações internacionais seja uma disciplina "autônoma", 
sobretudo depois dos trabalhos de Renouvin e Duroselle, colocam-na numa posição subalterna, instrumento para a teoria. Esses dois historiadores franceses, cientes de que os exemplos históricos foram e são utilizados como apoio a reflexões teóricas, e sem negar o valor desses estudos, ressalvaram que [aqui eu gostaria de ler um pequeno trecho] "em vez de procurar na história um elemento de sustentação a conceitos já elaborados, acreditamos fosse mais sensato investigar o passado, a fim de estabelecer as constatações permitidas pelo estudo dos documentos; poderemos assim, é certo, fornecermos materiais ou motivos de reflexão aos teóricos das relações internacionais, mas levamos a cabo nossas pesquisas sem nos deixar guiar por este tipo de preocupações”. Outra concepção de Renouvin e Duroselle a reter é o fato de considerarem o Estado como o centro das relações internacionais. Não obstante o estudo das relações internacionais abrangerem relações entre povos e entre indivíduos, intercâmbio de produtos, serviços, ideias, influências de formas de civilização, tais relações não podem ser vistas de modo isolado das relações que existem ao nível dos Estados, pois estes, no mais das vezes, é que regulam, limitam e/ou orientam tais relações. Outra constante na obra desses dois autores e seus seguidores é a repulsa a qualquer tipo de mecanicismo, e a insistência na particularidade de cada ação concreta. As análises devem ser feitas caso a caso, pois os móveis da ação variam conforme a época e o lugar onde ocorrem, levando-se em conta a conduta do estadista, informada que é pelas suas concepções pessoais, métodos de ação, relações sentimentais...

Conclui-se, portanto, que há uma nítida interdisciplinaridade entre história e teoria das relações internacionais. Ao historiador não lhe é permitido ignorar os trabalhos dos teóricos, mesmo porque o conhecimento do funcionamento do sistema internacional e a absorção de conceitos utilizados pelos teóricos são fundamentais para a análise do historiador. Da mesma forma, toda teorização que prescindir da perspectiva histórica, isto é, que não for estribada no concreto histórico bem estabelecido, corre o risco de ruir ao primeiro sopro, independentemente de sua rígida coerência interna. Premissas falsas levam às conclusões equivocadas. Resumindo: o teórico das relações internacionais ocupa-se do sistema internacional, com a atenção voltada para o presente e com a preocupação de estabelecer generalizações, buscar o permanente e durável, dir-se-iam "leis"que regulam o sistema internacional, com vistas a perceber tendências de seu comportamento e propor alternativas ao seu curso.

Finalmente, fiel que somos à noção de que o processo histórico é algo totalizado, não vislumbramos a possibilidade de a História das Relações Internacionais constituir-se em disciplina autônoma. O real só comporta facetações para efeitos de análise. Essa facetação do concreto leva a um obvio desdobramento da História como disciplina, tais como: econômica, social, política, da arte, das mentalidades, demográfica ... Neste sentido, 
e só neste sentido, é que existe uma História das Relações Internacionais.

PERGUNTA: Especificamente sobre a influência da Escola dos Annales e da Nova História, como ela se deu na sua produção intelectual?

Clodoaldo Bueno: Os meus professores, quase todos, concebiam o processo histórico na forma proposta pelos adeptos da Escola dos Annales. Ou você faz história dos Annales ou faz aquela história superada, que alinhava tratados e outros atos internacionais sem construir uma explicação apoiada nas forças profundas.

PERGUNTA: A obra História da política exterior do Brasil, produzida em conjunto com o professor Amado Cervo, se converteu na síntese mais importante e disseminada acerca das relações exteriores do país, de tal forma que parece impossível algum estudante se formar na graduação em Relações Internacionais sem ter tido contato com o livro. Depois de quase três décadas desde seu lançamento, como o senhor avalia o impacto dessa iniciativa?

Clodoaldo Bueno: Não havia então uma história da política externa brasileira sistematizada como nós fizemos. Existiam dois bons manuais: o de Hélio Vianna e o de Delgado de Carvalho, geógrafo que elaborou um compêndio didático, que por bom tempo foi um manual da disciplina de história das relações diplomáticas do Brasil do Instituto Rio Branco. As informações factuais fornecidas por ambos os autores, são firmes. Nosso objetivo foi elaborar uma síntese interpretativa na política externa brasileira a partir da análise controlada das fontes, o que nos deu base factual, isto é, uma interpretação arrimada no concreto histórico. Toda a periodização que lá existe é exclusivamente nossa. Periodizar faz parte da teorização, pois requer uma visão de conjunto para se distinguir as linhas básicas de um processo histórico, perceber as mudanças nos eixos que o conduz. A ideia inicial foi do Amado. Confesso que relutei a princípio, pela relativa carência à época de textos específicos sobre determinados períodos, mas também pelo receio de entrar numa empresa desse porte na qual se exige o controle das informações fornecidas pelas fontes, pois nem sempre uma fonte autêntica é veraz. Isto vale para fontes primárias e, sobretudo, para fontes bibliográficas. $\mathrm{O}$ fato de o Amado e eu já então possuirmos trabalhos originais solidamente calçados em fontes, contribuiu, em grade medida, para a viabilização do projeto.

PERGUNTA: Ainda falando sobre a obra. A História da Política Exterior do Brasil, o tema do desenvolvimento nacional foi fundamental. O senhor entende que houve uma influência cepalina nessa escolha? E, se sim, como foi esse contato? 
Clodoaldo Bueno: Não houve influência cepalina. Com maior ou menor ênfase, a luta pelo desenvolvimento nacional foi uma constante da política externa brasileira, desde o Império.

PERGUNTA: Muita gente enquadra o senhor como um discípulo da escola francesa e como um cepalino, não é? O que o senhor pensa sobre isso?

Clodoaldo Bueno: Respeito muito a produção dos cepalinos, mas ela não teve qualquer influência na minha produção intelectual. Se você observar o sumário de minha parte no $A$ política externa brasileira, verá que apenas o título do item relativo ao desenvolvimentismo associado coincide com uma expressão usada pelos cepalinos. Frase que sintetiza uma época, mas não era exclusiva dos analistas da Cepal.

PERGUNTA: Porém, o vocabulário utilizado pelo senhor é muito parecido com o marco 'cepalino' e o uso da baliza do desenvolvimento como um fator qualitativo.

Clodoaldo Bueno: Minha formação vem dos mestres franceses da escola dos Annales já citados e de outros autores da mesma linhagem intelectual, recebida de meus professores e de leituras. Meses depois que concluí a graduação, veio a público (1967) no Brasil a tradução da Introdução à história das relações internacionais de Renouvin e Duroselle. Esses autores trabalharam na mesma linha dos Annales. O método de trabalho usado por Renouvin e Duroselle vai ao encontro da diatribe de Lucien Febvre contra a "velha história diplomática” no seu Combats pour L'Histoire.

PERGUNTA: O que o senhor imagina do seu legado intelectual e como também figura pública intelectual? Como imagina ser o seu legado intelectual?

Clodoaldo Bueno: Amado Cervo e eu fomos pioneiros no despertar da nova historiografia das relações internacionais no Brasil. Já havia bons textos elaborados por diplomatas e historiadores diletantes, mas esparsos sobre assuntos específicos. A academia não tinha interesse pela área por desconhecimento dos novos estudos, o que a levava a confundir história das relações internacionais com a velha história diplomática. Há, como se sabe, modismos no nosso ambiente. Nos principais centros universitários, os interesses dos jovens futuros historiadores estavam voltados para outras áreas e temas - importantes e sedutores, sem dúvida - como os que se abrigam na história social, na economia, nas mentalidades. O advento do Mercosul e a formação dos megablocos em outras áreas do planeta deram lugar 
aos debates sobre suas consequências em encontros internacionais integrados por diplomatas, acadêmicos, políticos e de expoentes da iniciativa privada interessados nas oportunidades que se abririam com a formação do bloco. Integração, cadeias produtivas e assuntos conexos deram nova dimensão aos estudos sobre Relações Internacionais entre os historiadores, polítólogos, economistas, e ganhou a grande mídia. Uma das decorrências desse interesse, é a pletora de cursos de relações internacionais hoje existentes no País.

Ademais, nada a reclamar. Considerando as dificuldades que tive que vencer desde menino, considero-me um vitorioso. Mas gostaria de ter feito mais como orientador. Quando eu comecei a trabalhar no curso de pós-graduação em poucos candidatos tinham interesse pelas relações internacionais. Tive orientandos bons de História, mas que trabalharam com temas de natureza diversa das relações internacionais. Não deu para formar uma equipe. Sempre fiz tudo sozinho. Em verdade, nunca me preocupara com isto, em razão do meu gosto pelo manuseio das fontes, selecioná-las, senti-las, conferir, anotar com cuidado, transcrever, interpretar. Por isso meu trabalho é mais lento do que a média dos meus colegas. Quando foi instalado o curso de pós-graduação "San Tiago Dantas" tive oportunidade de orientar somente alunos da nossa área. Recebi orientandos com elevado potencial, bem-preparados e vocacionados. Isto para mim foi muito gratificante. Não posso me queixar, pois tenho a satisfação de os ver progredindo cada vez mais como docentes ou pesquisadores, recebendo prêmios, frequentando grandes centros que cultivam os estudos das relações internacionais. Estaria lá ainda lecionando se morasse na Capital, mas viajar com frequência Marília-São Paulo-Marília é cansativo. Sinto falta do convívio com os colegas e dos alunos.

Recebido: 22/08/2021

Aceito: $20 / 11 / 2021$

Publicado: 18/02/2022

\footnotetext{
${ }^{i}$ Doutor em Relações Internacionais pelo Programa de Pós-Graduação em Relações Internacionais San Tiago Dantas (UNESP, UNICAMP e PUC-SP). Coordenador do Grupo de Análise de Conjuntura Internacional vinculado ao IPECI (Instituto de Pesquisas Científicas e Tecnológicas) e professor de Relações Internacionais e Histórica da Universidade Católica de Santos. https://orcid.org/0000-0001-7129-1077

${ }^{i i}$ Doutor em História pela Pontifícia Universidade Católica do Rio Grande do Sul (PUCRS) na Linha de Pesquisa "Sociedade, Política e Relações Internacionais" com estágio doutoral "sanduíche" na Universidad Complutense de Madrid. É Professor Adjunto de História das Relações Internacionais e de História da Política Externa Brasileira na Universidade Federal do Rio Grande (FURG). https://orcid.org/0000-00015584-9747
} 